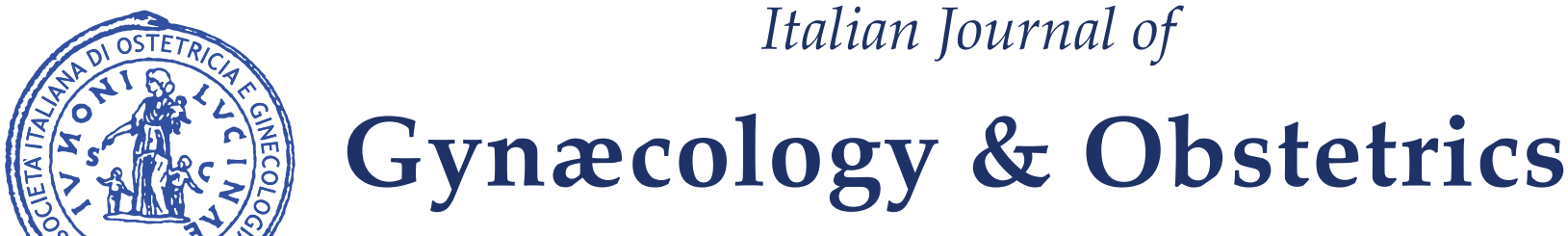

March 2021 - Vol. 33 - N. 1 - Quarterly - ISSN 2385 - 0868

\title{
Bacillus Calmette-Guerin (BCG) in immunotherapy of ovarian tumors: from the beginning to recent findings. May it still be relevant?
}

\section{N. G. Carretti ${ }^{1,2}$}

${ }^{1}$ Faculty of Medicine, Department of Molecular and Developmental Medicine, University of Siena, Siena, Italy

${ }^{2}$ Former Research Fellow in the Department of Immunopathology, New York University School of Medicine, New York (N.Y.), USA

\section{ABSTRACT}

Bacillus Calmette-Guerin (BCG) is still the most used form of vaccination against virulent Mycobacterium tuberculosis (Mt) from 1921. Inactivated Mt is capable to induce an immune response principally on T1 lymphocytes in experimental animal (Freund complete adjuvant) and in men (BCG). In 1970 it was thought that inducing this response by intradermal or intratumoral BCG might have been useful in the treatment of advanced ovarian carcinoma. This study was published in 1974 . In 1976 intracavitary BCG was first applied in the treatment of superficial bladder tumors; in 1990 its use was accepted by the U.S. Food and Drug Administration and still now it represents the golden therapy for this kind of tumor. Recently a derived BCG cell wall skeleton (SW-BCG) preparation was used intracutaneously in ovarian cancer patients after surgical removal of tumors with lymphoadenectomy. It was seen that lymphoadenectomy causes a significantly reduced survival as a sign of a decreased immune response. Although BCG use in human tumors, like bladder cancer, is still relevant, many other important discoveries of inhibitors of immunity cellular checkpoint (CTLA-4, PD-1) in human immunotherapy have been successfully done in the last years. Nevertheless BCG, which was used first, has represented and still represents a model for cancer immunotherapy and its mechanism of action is not fully understood: BCG might act stimulating the immune response of $\mathrm{T}$ lymphocytes mobilization, modifying the TA expression, removing the immune defense blocking

\section{SOMMARIO}

Il Bacillus Calmette-Guerin (BCG) è la forma di vaccinazione più utilizzata nell'uomo contro la tubercolosi da Mycobactierium (Mt) dal 1921 ai giorni nostri. Il Mt inattivato è in grado di indurre una risposta immunitaria principalmente sui linfociti $\mathrm{T} 1$ negli animali da esperimento (come adiuvante completo di Freund) e negli uomini (BCG). Nel 1970 si è pensato che, provocando questa risposta con l'uso di BCG intradermico (i.d.) o intratumorale, ciò avrebbe potuto essere utile anche nei tumori solidi umani, in particolare nel trattamento di stadi avanzati di carcinoma ovarico e nello studio della reattività alla tubercolina o agli antigeni dello stesso tumore. I risultati di questa indagine, eseguita nella Clinica Ostetrica e Ginecologica dell’Università di Padova sono stati pubblicati negli Atti del 56 ${ }^{\circ}$ Congresso SIGO, nel 1974.

Nel 1976 il BCG è stato poi proposto con trattamento intracavitario per la prima volta nel carcinoma della vescica superficiale e nel 1990 il suo uso è stato accettato dalla Food and Drug Administration (USA) e ancora oggi rappresenta la terapia prescelta in questo tipo di tumore vescicale. Recentemente la preparazione della parete cellulare del BCG (SW-BCG) è stata utilizzata per via sottocutanea per testare l'effetto della linfoadenectomia nel carcinoma ovarico: è stata osservata altresì una significativa correlazione della linfoadenectomia con una ridotta sopravvivenza delle pazienti.

Benché l'uso del BCG in alcuni tumori, come il cancro alla vescica, sia ancora attuale, sono stati fatti molti altri importanti progressi, soprattutto riguardanti inibitori dei checkpoint cellulari 
and making TA recognizable by more stimulated CD-8T and NK cells. BCG might be successfully associated to anti PD-1 or CTLA-4 cancer immunotherapy in non-responding patients, since they have different mechanisms of action, to give a more active and potent immune response.

Corresponding Author: Nicola Carretti

E-mail: nicola.carretti@gmail.com

Copyright 2021

DOI: $10.36129 /$ jog.33.01.02 dell'immunità (CTLA-4, PD-1), e l'immunoterapia è stata eseguita con successo in molti tipi di tumori umani negli ultimi anni. Tuttavia, il BCG ha rappresentato e rappresenta ancora un modello di indagine per la reattività immunitaria e il suo meccanismo d'azione non è del tutto compreso: il BCG potrebbe agire stimolando la risposta immunitaria dei linfociti $\mathrm{T}$, modificando l'espressione degli antigeni tumorali (AT), rimuovendo alcuni blocchi immunodifensivi e rendendo l' AT più riconoscibile dalle cellule CD-8T e NK così stimolate. In studi recenti si ritiene che il BCG potrebbe essere associato con successo agli inibitori dei checkpoint immunitari PD-1 e CTLA-4 nei pazienti che non rispondono o che hanno delle recidive dopo tali terapie.

Key words:

Bacillus Calmette-Guerin (BCG); human immunotherapy; ovarian tumors; others malignancies; tumor's T-lymphocytes response.

\section{INTRODUCTION}

Bacillus Calmette Guerin (BCG) is a bovine inactivated and not virulent tubercular bacillus used for years to immunize against the diffusion of tuberculosis due to the infection of virulent Mycobacterium tuberculosis (Mt) and firstly administered in human beings in 1921.

BCG is the only vaccine against tuberculosis. It is the most widely administered vaccine and usually a part of the routine newborn immunization schedule. BCG vaccine also offers protection against non-tuberculous mycobacteria infection like leprosy and Buruli ulcer. BCG vaccine is safe and is not associated with severe complications (1).

Only in the last fifty years, starting from 1970, it was proved that BCG vaccine does not only protect against tuberculosis, but its use also produces benefits against other bacterial diseases (2), decreases the incidence of allergic diseases (3) and is useful in the treatment of certain malignancies $(4,5)$. Despite its limitations, to date in bladder cancer it has not been surpassed by any other treatment (6). An evolution from topical BCG intravesical administration, which was first approved by the U.S. Food and Drug Administration in 1990, to PD-1/PD-L1 immunotherapy has been recently reviewed (7). The aim of this review in the light of other experiences, is to look at a possible role of BCG or its derivatives in cancer immunotherapy, in particular in ovarian cancer where it was firstly proposed, in addition to immunotherapies with anti-checkpoint inhibitors.

\section{BCG use in human solid tumors}

\section{Ovarian tumors}

Use of BCG in solid malignancies started with ovarian tumors in 1970 in the Obstetric and Gynaecological Clinic of the Padua University where 19 patients with advanced ovarian carcinoma were tested with the intent of improving the lymphocytes response against cancer by intradermal or intratumoral BCG injections (8-10). In these patients BCG was injected in 16 patients weekly by repeated intradermal injections (indirect administration) and in 3 cases by direct intratumoral injection (direct intraparenchymal injections). In two of these patients BCG was injected into subcutaneous metastatic nodules after having boosted them twice intradermally; in the third, BCG was injected in the proper tumor parenchyma inside the peritoneal cavity.

The initial approach was to attack the ovarian tumor using BCG intradermally or in the site of the same tumor thus initiating, eliciting, and improving an immunogenic response to tumor similarly to what observed in experimental animals with the use of Freund complete adjuvant (which contains 
also killed Mt in a mineral oil solution). This would have happened through a modification of surface tumor antigen presentation and recognizing, and activating lymphocytes T-cell responses, lymphocytic infiltration into tumors and cell death. In fact, cell-wall skeleton (CWS) fraction was found to be the major adjuvant-active principle of mycobacterial cells which were used in Freund's complete adjuvant (FCA). It was than suggested that dendritic cells and macrophages express two sorts of receptors, Toll-like receptors, TLR-2 and TLR4 , and a putative binding receptor for BCG-CWS, whose signaling pathways lead to a sufficient antigen-presenting state in the activation of the innate immune system $(11,12)$.

\section{Intradermal BCG (indirect) and intradermal tumor} homogenate testing reaction

16 patients of variable age, from $28 \mathrm{y}$. to $62 \mathrm{y}$. were studied. All with gynaecological malignancies (8 ovaric, 7 cervical carcinoma, 1 endometrial). All these patients had been previously treated surgically or by radiant therapy, judged in an advanced stage of the disease and no longer treatable. They were preliminary tested with intradermal (i.d.) injection of $0.1 \mathrm{ml}$ tuberculin (Mantoux reaction) and 14 were found negative and 2 weakly positive (-+-). The tumor homogenate was prepared as reported by Kaham B.D. (13). BCG vaccination was done by intradermal injections or by grating dermal scarification. After the first BCG vaccination $14 / 16$ patients had a response to BCG vaccination, 8 weak $(1+)$, 4 mild $(++)$, and 2 strong $(+++)$. Repeated vaccinations (two to three every week) with $0.1 \mathrm{ml}$ dose determined a very strong reaction in 13 patients; two on which BCG was used form dermal scarification (30 $\mathrm{mg}$ bacterial patina each) had high temperature $\left(39-40{ }^{\circ} \mathrm{C}\right)$ for one day and vomit.

It was then thought that it would be interesting to test the skin anti-tumor homogenate in the patients in which dermal reaction to BCG was found improved: in other words, to see if the skin reaction against BCG might have elicited also some reaction against the homogenate preparation of tumor cells of the same women. All these patients were found, before initiating BCG, preliminary negative to i.d. injection of their own tumors.

Only in two patients, which had been BCG negative and then BCG positive (one cervical carcinoma and one ovarian bilateral Krukenberg tumor), the tumor homogenate determined an intradermal reaction, the first with a diameter of $8 \mathrm{~mm}$ after 24-48 hours, interpreted as delayed hypersensitivity reaction to tumor); in the other patient after 48 hours an infiltrate erythematous (classified ++-) was present. These cases were the first preliminary experimental evidence that in solid gynaecological advanced tumors in all the 19 patients admitted to the study there was an absent or weak (less than one plus), tuberculin i.d. reaction.

This reaction can be changed to a very strong one after repeated (2 to 3 ) vaccinations with BCG.

This delayed hypersensitivity reaction obviously acts primarily against BCG but also, in few cases $(2 / 16)$ in our experience, against its own tumor antigen homogenate showing a delayed hypersensitivity cancer i.d. reaction (DIX) evident after 48 hours, when this DIX was absent before the BCG vaccination.

Thus, BCG repeated intradermal vaccinations may indirectly improve also an anti-tumor response in a minority of previously non-responding patients. This observation may have some importance and take some place for the proposal of supporting with BCG i.d. boosting other kind of immunotherapies when there is some relapse or loss of efficacy of the immunotherapy chosen primarily.

\section{Intratumoral (i.t.) BCG injection (direct)}

These studies have been a direct consequence of the first 16 reported in point 1 and are briefly described here:

a. in the first case (F.N. 48 y.) (at TIII N1 stage) 30 mg. of BCG were injected at open abdomen just in thickness of main tumor mass in the omentum. Metastases were observed in the intestine and in the peritoneum. The carcinoma was histologically judged of probable intestinal origin. BCG showed no apparent regression of the tumor and the patient deceased apirectic due to abdominal and pulmonary carcinomathosis after 5 months.

b. In the second case (S.M.30 y.), with an initial totally absent tuberculin reaction, BCG was injected i.d. at weekly intervals with $30 \mathrm{mg}$ of bacterial patina (b.p.) each time such determining a very intense local reaction $(+++)$. It was then decided to make the BCG injection directly in two parasternal visible metastatic nodules, with the aim of addressing the lymphocytes reaction against the tumor cells: this was done twice, at a distance of a week, the first with $6 \mathrm{mg}$, the second with $15 \mathrm{mg}$ of b. p. After 4 hours of the $2^{\text {nd }}$ injection followed a rise in temperature (up to $40{ }^{\circ} \mathrm{C}$ ) that decreased in the afternoon (figure 1). This young women was at almost ter- 
minal stage with pleural bilateral effusion and bone metastasis radiologically diagnosed of an advanced granulous ovarian carcinoma and weighted $35 \mathrm{Kg}$ After having left the hospital, this patient regained $10 \mathrm{Kg}$ of weight and her general conditions improved in an unexpected way; her life was prolonged of one year. Then tumor relapsed after she refused other advised boost treatment with BCG.

c. In the third patient (D.B.G., 57 y.), not judged susceptible to any known therapy, BCG was directly injected into the parenchyma of an advanced great ovarian tumor with peritoneal metastasis (stage T III) only once at a dose of $30 \mathrm{mg}$, after opening the abdominal wall to visualize the peritoneal cavity and the actual state of the tumor with an explorative laparotomy. The body temperature of this patient in the days after the BCG intratumoral injection is shown in the reported figure (figure 2). No chemotherapy was used. This patient left the Hospital after 48 days with an apparent complete recovery and the clinical disappearance of the tumor, which was before seen and histologically demonstrated. This patient survived 10 years, there has been no return of the tumor and she died of heart attack. At my knowledge, these cases represent the first reports that BCG influences, changes or improves the clinical behavior in human solid tumors - gynaecological in the described ones - most probably after having changed the immune response against them. This reaction has been obtained with direct intratumor injections of visible parasternal nodules done after a previous i.d. boosting in the patient (S.M.) and with a single injection of $30 \mathrm{mg}$ of BCG inside the tumor's parenchyma, in a very advanced case of ovarian cancer with multiple peritoneal metastasis, in the other patient (D.B.G.). This approach led to complete and definitive recovery of patient D.B.G., who survived tumor-free for 10 years without any further chemotherapy or surgery, and to an unexpected one year survival in the other patient (S.M.) with visible clinical improving and a $10 \mathrm{~kg}$. weight gain. In the last patient

\section{PATIENT S.M.}

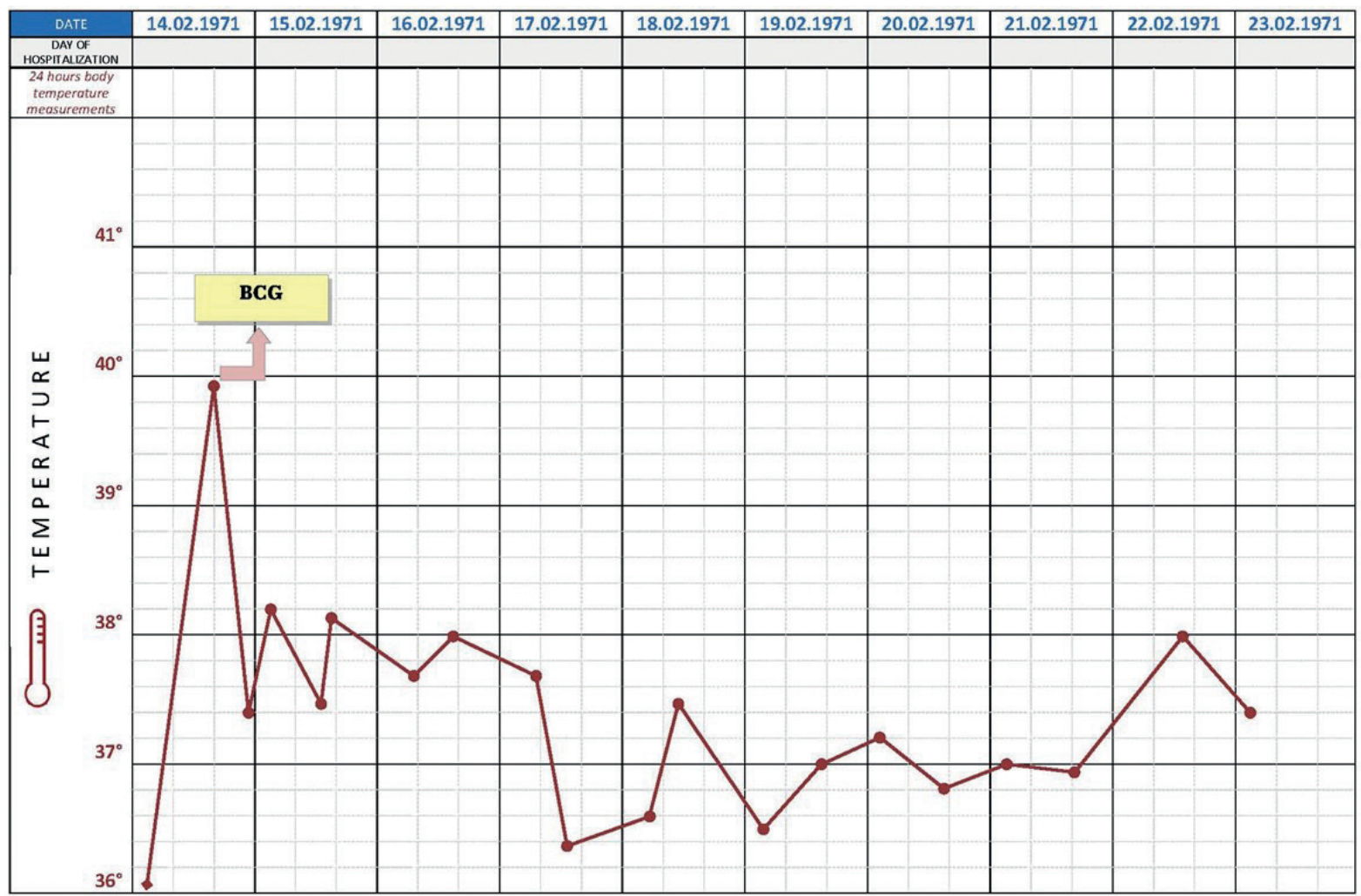

Figure 1. Behavior of body temperature after intralesional administration of BCG in patient S.M. (30 y.). 
(F.N.) BCG seemed to have no evident clinical effect and this patient survived 5 months.

\section{Immunotherapy in ovarian cancer}

These first reports were confirmed by successive studies: over the course of time the presence of $\mathrm{T}$ cells within the epithelial component of tumors (TILs), as histologic evidence of anti-tumor immunity has been associated with a survival advantage. It was also demonstrated that intraepithelial TILs are robust predictors of outcome in ovarian cancer and define a specific class of patients, whose distinct tumor biology should be taken into account in devising appropriate therapeutic strategies.

There are not enough data about BCG used alone in different types of ovarian cancers and in concomitance or in absence of other therapies (surgical, chemotherapy, anti-PD-1, etc.), but since BCG elicits T-cell response, an indirect answer to this question may be found in the reported study on the prognostic significance of tumor infiltrating T-cell (TILs) in ovarian cancer regarding 1815 pa- tients which is, to my knowledge, the most complete and convincing about the matter.

The characteristic of the study refers to more than $70 \%$ of the patients Stage III-IV. The article doesn't concern BCG use, but as a matter of fact, BCG stimulates TILs infiltration. A lack of intraepithelial TILs is significantly associated with a worse survival among patients as shown in the table reported in the same paper which shows the experience of many countries (pooled HR: 2.24, 95\% CI; 1.71-2.91) (14). It was recently proposed a standardized methodology to assess tumor-infiltrating lymphocytes (TILs) in other solid tumors, as Melanoma, Gastrointestinal Tract Carcinomas, Non-Small Cell Lung Carcinoma and Mesothelioma, Endometrial and Ovarian Carcinomas, Squamous Cell Carcinoma of the Head and Neck, Genitourinary Carcinomas, and Primary Brain Tumors (15). Lack of TILs within the tumors represent always a negative factor for the prognosis. It was reported that in 73 patients with ovarian cancer in which, after surgical removal of tumors with lymphoadenectomy, a cell skeleton of

PATIENT D.B.G.

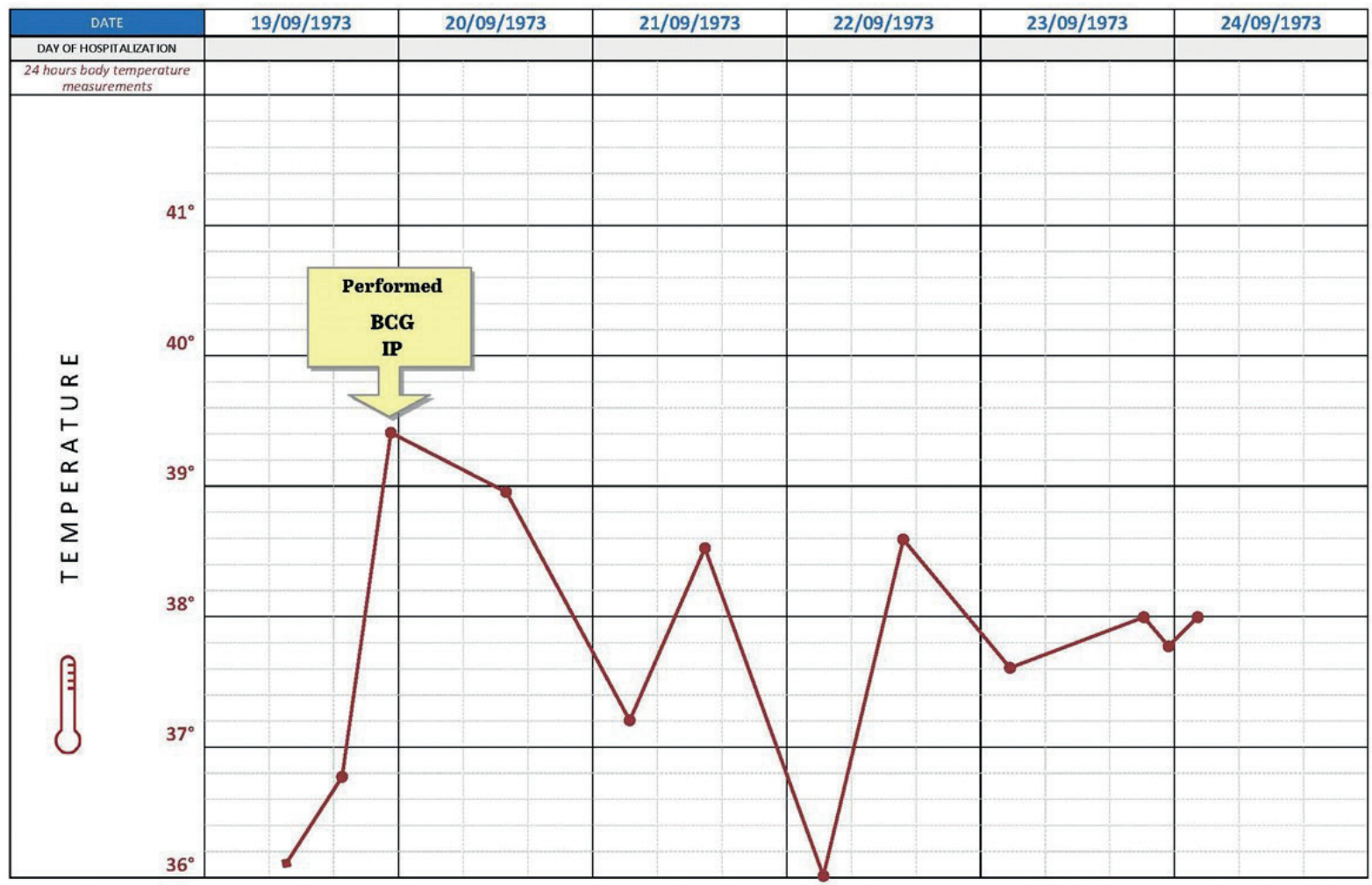

Figure 2. Behavior of body temperature after intralesional injection of BCG in patient D.B.G (57y). 
BCG was inoculated intracutaneously, a significantly reduced survival of patients was observed. In view of the importance of the role of lymph nodes in the stimulation of Toll-like receptors by BCGCWS, it is suggested that lymph nodes should be kept as much as possible to preserve the patient's immunity against cancer (16). Other results suggest that mycobacterial CWS as a universal vaccine vehicle for conjugation of a wide variety of antigens, as Mt derived, constitutes a breakthrough for development of the most promising vaccines for infections, allergic diseases, and cancer (17-19). In 1999 were published the results of multiple immunotherapy with BCG with other adjuvants (Cley's vaccine, mixed bacterial vaccine, transfer factor and lymphoblastic limphocytes) in 52 patients treated between 1991 and 1997) in different types of cancer at different stages. Apparently this immunotherapy was given not intraparenchymally, not only BCG was used and many patients had undergone other therapies (surgical and others). The cases to be considered "successful" were 4 over 52: Hodking disease, adenocarcinoma of esophageal junction (who received also surgery), a prostate adenocarcinoma who made also the traditional therapy's case of generalized carcinoma of the ovary (20).

Since ovarian cancer is the fifth leading cause of cancer death among women and the most lethal gynaecologic malignancy, enormous progress has been made in the management of this disease. Immune checkpoint inhibitors offer a potential for improved survival. A variety of strategies are possible using new agents and the paper focuses principally on phase III and ongoing trials. New immunotherapeutic approaches based on immune checkpoint inhibitors are currently changing the landscape in melanoma treatment, however, in ovarian cancer, potential success of this therapy relies on better understanding of tumor microenvironment and dominant immunosuppressive pathways, as well as finding reliable biomarkers. So far, described biological drugs and new therapeutic approaches were not shown to cure ovarian cancer, but they bring the long-awaited promise of turning it into a manageable chronic disease (21).

\section{Intraperitoneal, gastric, colon cancer}

In 1983 Corynebacterium paroum was given intraperitoneally (i.p.) in human ovarian carcinoma in 14 cases of advanced ovarian tumors. Administration of C. parvum i.p. has augmented the ability of human peritoneal cells to lyse human ovarian car- cinoma cell lines in the presence of specific rabbit antiserum. In 5 patients out of 11 treatments with C. parvum produced surgically confirmed tumor regression (45\%) with 2 complete responses (22). Systemic Corynebacterium paroum has limited activity in gynaecologic malignancies. Although intraperitoneal C. parvum is active, its toxicity is prohibitive. Intraperitoneal alpha-interferon is an active second line agent for minimal residual disease following combination chemotherapy. Intraperitoneal interferon trials are ongoing. The presence of intratumoral $\mathrm{T}$ cells independently correlated with delayed recurrence or delayed death in multivariate analysis was associated with increased expression of interferon-gamma, interleukin-2, and lymphocyte-attracting chemokines and with best survival in tumor patients. The presence of intratumor $\mathrm{T}$ cells correlates with improved clinical outcome in advanced gastric and ovarian carcinoma. (23-25). The use of BCG is aimed at improving the T lymphocytes presence in the context of the tumor. BCG responsiveness is believed to be linked to a large number of tumor infiltrating lymphocytes, not only ovarian but also gastric cancer. Surgery reception before BCG may ameliorate the prognosis. A total of 156 patients with stage III or IV gastric cancer who had undergone curative resection were randomly assigned to three treatment groups: BCG + FAM (immunochemotherapy), FAM (chemotherapy), and control (surgery only). In patients with pT2/T3 primary tumors, 10-year survival was 55.3\% for BCG + FAM vs $28.2 \%$ for FAM $(\mathrm{P}<0.01)$ and $14.6 \%$ for the control group $(\mathrm{P}<0.00018)$. This study, based on a limited number of patients, indicates that adjuvant immunochemotherapy (BCG + FAM) may prolong the survival of gastric cancer patients after curative gastrectomy; in particular, in patients with $\mathrm{pT} 2 / \mathrm{T} 3$ tumors and intestinal-type primary tumors (26).

Treatment of gastric peritoneal carcinomatosis by combining complete surgical resection of lesions and intraperitoneal immunotherapy using Catumaxomab, a nonhumanized chimeric antibody, is characterized by its unique ability to bind to three different types of cells: tumour cells expressing the epithelial cell adhesion molecule (EpCAM), T lymphocytes (CD3), and also accessory cells Fcy receptor. Because the peritoneum is an immunocompetent organ and up to $90 \%$ of gastric carcinomas express EpCAM, intraperitoneal infusion of Catumaxomab after complete resection of all macroscopic disease (as defined in the treatment of carcinomatosis from colorectal cancer) could therefore 
efficiently treat microscopic residual disease (27). Bacillus Calmette Guérin (BCG) has a potential anti-tumor effect on gastric cancer, however, the mechanism is still unclear. An experimental study (27) investigated the effect of BCG on gastric cancer cell line MGC-803 and studied the potential cooperation of BCG and lymphocyte in determining the final fate of cancer cells. After treatment with BCG, the cell viability was significantly inhibited in a dosage-dependent manner. Flow cytometry assay showed that apoptosis rates were significantly increased by BCG.

It was found that BCG induced secretion of interferon gamma (IFNg) from lymphocytes. BCG promotes lymphocyte immunocompetence to induce cell apoptosis and autophagy in MGC-803 cells, inducing the release of IFNg from peripheral blood lymphocytes (28).

As far as colon cancer is concerned, macropinocytosis has emerged as an important pathway of protein acquisition in cancer cells, particularly in tumors with activated Ras such as pancreatic and colon cancer. Macropinocytosis is also the route of entry of Bacillus Calmette-Guerin (BCG) and other microbial therapies of cancer. Using BCG uptake to assay macropinocytosis, we executed a genome-wide shRNA screen for macropinocytosis activators and identified Wnt pathway activation, which is a main regulator of development throughout the animal kingdom, is seen as a strong driver of macropinocytosis (29). In conclusion, it was suggested that the Wnt pathway is a previously unappreciated driver of macropinocytosis in cancer.

With a multicenter, randomized controlled phase III clinical trial in Stages II and III colon cancer, patients with active specific immunotherapy (ASI) using autologous tumor cells with an immunomodulating adjuvant bacillus Calmette-Guerin (BCG) vaccine (OncoVAX) in an adjuvant setting, it was seen that surgery alone cures approximately $65 \%$ of Stage II (Dukes B2, B3) colon cancer patients. In the remaining patients, OncoVAX in an adjuvant setting, significantly prolongs recurrence-free interval (57.1\% relative risk reduction) and significantly improves 5 -year overall survival and recurrence-free survival. This study verified that the use of OncoVAX for patients with Stage II colon cancer not only has significant prognostic benefit and positive clinical outcomes, but also showed that OncoVAX therapy yields impressive health economics benefits (30).

In a very recent report, done using cell wall skeleton of BCG (cws-BCG) in 18 patients with ad- vanced WT1-expressing cancers refractory to standard anti-cancer therapies (7 melanoma, 5 colorectal, 4 hepatobiliary, 1 ovarian, and 1 lungs), was found a dose-limiting toxicity which occurred in the form of local skin reactions in 2 patients at a dose of $200 \mu \mathrm{g}$ although no serious treatment-related systemics AEs were observed. Some patients demonstrated the induction of the CD4 T cell subset and its differentiation from the naïve to memory phenotype, resulting in a tumor response. The RD of BCG-CWS was determined to be $100 \mu \mathrm{g} /$ body. This dose was well tolerated and showed promising clinical effects with the induction of an appropriate immune response (31).

\section{Bladder tumors}

After 4 decades of use, BCG remains the most effective agent against high risk NMIBC, but it still holds substantial drawbacks. The enduring use of immunotherapy for NMIBC has created a propitious environment to search for better alternatives. There is an increasing number of promising in vitro, animal and early human clinical trials to anticipate a significant therapeutic alternative in the foreseeable future (31). This procedure, in which BCG enters directly in contact with malignant cells was, with the same intent, subsequently applied to bladder cancers with intravesical administration of BCG by intraurethral way of the bladder tumor (published in 1976) (32). In 1990, the U.S. Food and Drug Administration approved the use of intra-vesical BCG for patients with superficial bladder cancer, and this procedure is the recommended standard of care for highgrade non-invasive bladder cancer worldwide (33). The history of BCG and bladder cancer as an immunotherapy of success was then reviewed by Harry and Co (34).

Intravesical therapy with bacillus Calmette-Guérin has proven effects for reducing recurrence, progression, and death from non-muscle-invasive bladder cancer. These advantages are seen mainly when appropriate maintenance therapy is used for 1-3 years, in the context of appropriate patient selection, tumor management, and symptom support for potential side effects (35).

This procedure is still in use and represents the main immunotherapeutical approach in bladder papilloma cancer and is regarded as a golden standard in high and intermediate-risk non muscle invasive bladder cancer. Unfortunately, up to $40 \%$ of patients might experience treatment failure. Immune checkpoint inhibitors emerge as new 
immunotherapeutics, which in the future might be combined with BCG and may serve as an alternative to radical cystectomy in patients, who failed to respond to BCG alone (37).

At this proposal some points have to be underlined:

1. BCG in bladder cancer works in about the half of the patients;

2. it has effect through direct contact with cancer cells;

3. sometimes the immune response declines with time but can be restored by repeated BCG intravesical boosting;

4. it is not known if an intradermal BCG repeated vaccination might sustain indirectly an anti-cancer direct immunotherapy.

We must then reiterate the conclusion that a certain, though unknown importance should be apparently given to the direct BCG action by intimate contact with tumor cells as well in ovarian as in bladder cancer.

The direct contact of BCG with the tumor cells may change the expression of Tumor Antigens thus exposing a new formed antigen which may elicit the cellular $\mathrm{T}$ lymphocyte immune response and the aggression against the tumor in many patients.

\section{Melanoma}

Intratumoral immunotherapy has been used in melanoma in which the approach to skin visible tumor is simpler. BCG was used in locoregional immunotherapies and metastasis melanoma (38). Mycobacterium bovis Bacillus Calmette-Guerin (BCG) serves as an adjuvant therapy that induces the recruitment of natural killer $\mathrm{NK}, \mathrm{CD}^{+}$, and $\mathrm{CD} 8^{+} \mathrm{T}$ cells and contributes to antitumor immunity. BCG can be administered in combination with chemotherapeutic and immunotherapeutic agents and can be genetically manipulated to produce recombinant BCG (rBCG) strains (39). It has been recently recognized that BCG serves as an adjuvant therapy that induces the recruitment of natural killer $\mathrm{NK}, \mathrm{CD}_{4}^{+}$, and $\mathrm{CD}^{+} \mathrm{T}$ cells and contributes to antitumor immunity. BCG can be administered in combination with chemotherapeutic and immunotherapeutic agents thus increasing the immune response and improving patient survival in melanoma patients. Since early trials BCG based immunotherapy for melanoma consistently showed a trend toward improved clinical outcomes in patients treated with BCG compared with observation alone (40).

Other types of immunotherapy have been trained in this type of tumor. Talimogene laherparepvec
(T-VEC), a genetically modified herpes simplex virus type 1-based oncolytic immunotherapy, is the first oncolytic virus approved by the U.S. Food and Drug Administration for the treatment of unresectable melanoma recurrent after initial surgery and the efficacy and safety data from clinical trials of T-VEC both as monotherapy and in combination with immune checkpoint inhibitors has been proved. Responses were seen in both injected and uninjected lesions including visceral lesions, suggesting a systemic antitumor response. When combined with immune checkpoint inhibitors, T-VEC significantly improved response rates compared with a single agent; similar results were seen with combinations of checkpoint inhibitors and other intratumoral therapies such as CAVATAK, HF10, and TLR9 agonists. Thus, both BCG and T-VEC have been used intratumorally as immunostimulatory agents with the goal of tumor cell lysis, followed by release of tumor-derived antigens and subsequent activation of tumor-specific effector T cells (41).

As far as I know, in melanoma it was never tried to improve a depressed antitubercolin immune reaction aspecifically, boosting the patient with intradermal or subcutaneous BCG, before injecting BCG directly in the tumor mass, in association with other chemotherapy or immunotherapic approaches.

As a comment, it has to be said that intratumoral immunotherapy can also be done with oncolytic viruses or biology derivative vaccine that change antigen presentation of the tumor as it expected to happen with BCG. The question remains to understand if BCG and oncolytic viruses work with different mechanisms, the former perhaps privileging the immune response, the latter changing the TA presentation to lymphocytes.

\section{Lung cancer}

An interesting study has been carried out on the effect of coexistence of concomitant active tuberculosis in patients with non-small cell lung cancer (NSCLC). In fact, concomitant active tuberculosis (TBLC) resembles loco regional immunotherapy of tumor cell vaccine like BCG whose local administration within the lung is not practicable. This study compares the survival and immunological cell profile in TBLC over NSCLC alone and a total of 276 NSCLC were included for a one year period. It was found that the median survival of squamous cell carcinoma (SCC) with an active tuberculosis is significantly longer ( $p$ less than 0.01 ) than adenocarcinoma or undetermined NSCLC with TB. Ac- 
tive tubercolosis in SCC increases the expression of CD3, CXCR3 and IP-10. These results show a better survival outcome in NSCLC patients with active tuberculosis. This effect is likely connected with the concomitant presence and perhaps contact of active tuberculosis with the lung cancer cells $(42,43)$.

In table I the types of malignancies with priority BCG treatment and the main reported results are summarized.

\section{Association of BCG with immune checkpoint in- hibitors}

The release of negative regulators of immune activation (immune checkpoints) that limit antitumor responses has resulted in unprecedented rates of long-lasting tumor responses in patients with a variety of cancers. This can be achieved by antibodies blocking the cytotoxic T lymphocyte-associated protein 4 (CTLA-4) or the programmed cell death 1 (PD-1) pathway, either alone or in combination (44). The main premise for inducing an immune response is the preexistence of antitumor T cells that were limited by specific immune checkpoints. Most patients who have tumor responses maintain long-lasting disease control, yet one-third of patients relapse. Mechanisms of acquired resistance are currently poorly understood, but evidence points to alterations that converge on the antigen presentation and interferon- $\gamma$ signaling pathways. New-generation combinatorial therapies may overcome resistance mechanisms to immune checkpoint therapy. The release of negative regulators of immune activation (immune checkpoints) that limit antitumor responses has resulted in an undetectable way (45). A novel dendritic cell immunotherapy with i.t. administration of BCG-CWS-treated dendritic cells following tumor cryoablation could be used for the therapy of cancer patients with multiple metastases. But of the most important interest is to underline that the association of BCG with immune checkpoint inhibitors was found to improve in any case the anti-tumor response better than a single agent alone (46). A heat-killed preparation of Mycobacterium vac-

Table I. Types of malignancies with priority BCG treatment, references and main results.

\begin{tabular}{|c|c|c|c|c|}
\hline Type & Description & Authors & References & Notes \\
\hline Leukemia & $\begin{array}{l}\text { BCG after the graft of the } \\
\text { tumor }\end{array}$ & Mathé G, et al. & $\begin{array}{l}\text { Boll Ist Sieroter Milan. } \\
1971 \text { Jul-Aug;50(4):251-9 }\end{array}$ & $\begin{array}{l}\text { Improvement and increase of } \\
\text { survival in all children }\end{array}$ \\
\hline Ovarian cancer & $\begin{array}{l}\text { Intraparenchymal tumor } \\
\text { BCG injection, without any } \\
\text { surgery or chemotherapy at } \\
\text { inoperable stage 3-4 }\end{array}$ & $\begin{array}{l}\text { Carretti N, et al. ( } 3 \text { with } \\
\text { intralesional BCG, } 16 \\
\text { with i.d. stimulation) }\end{array}$ & $\begin{array}{l}\text { Atti del } 56^{\circ} \text { Congresso } \\
\text { Nazionale della Società } \\
\text { Italiana di Ostetricia e } \\
\text { Ginecologia. Padua, 3-5 } \\
\text { Oct 1974: pp. 465-8 }\end{array}$ & $\begin{array}{l}1 \text { complete recovery for } 10 \text { years } \\
1 \text { remission with } 1 \text { year survival } \\
1 \text { death after } 5 \text { months } \\
\text { No answer in } 16 \text { i.d. treated }\end{array}$ \\
\hline Bladder tumor & Superficial, non- invasive & Morales A, et al. & J Urol 1976;116: 180-3 & $\begin{array}{l}\text { Recommended by FDA in } 1990 \text { as } \\
\text { standard of care }\end{array}$ \\
\hline $\begin{array}{l}\text { Lung Cancer postop: } \\
\text { follow up report }\end{array}$ & $\begin{array}{l}\text { Intrapleural } \\
\text { BCG: } 5 \text { years follow up reports }\end{array}$ & Bakker et al. & $\begin{array}{l}\text { Cancer Immune } \\
\text { Immunother } 1986\end{array}$ & $\begin{array}{l}56 \text { p. treated no survival benefits at } \\
2 \text { and } 5 \text { years }\end{array}$ \\
\hline $\begin{array}{l}\text { Lung Cancer non- small } \\
\text { cells lung cancer post- } \\
\text { surgical stage I }\end{array}$ & Intrapleural BCG & Macchiarini $\mathrm{P}$, et al. & Anticancer Res 1989 & $\begin{array}{l}17 \text { p. no significant improvement } \\
\text { at } 5 \text { years }\end{array}$ \\
\hline Intraperitoneal & $\begin{array}{l}\text { i.p. alpha } 1 \text { interferon } \\
\text { Corynebacterium parvum } \\
\text { and IL-2 }\end{array}$ & $\begin{array}{l}\text { Foon KA, Fanning; Bast } \\
\text { J, et al. }\end{array}$ & $\begin{array}{l}\text { Cancer Research 43,1395- } \\
14011983 \\
\text { Semin Surg Onc } \\
\text { 1990;6(6):364-8 }\end{array}$ & $\begin{array}{l}\text { Limited activity } \\
\text { Prohibitive Toxicity Limited } \\
\text { experience }\end{array}$ \\
\hline $\begin{array}{l}\text { Ovarian Carcinoma } \\
\text { Stages III-IV }\end{array}$ & $\begin{array}{l}\text { Autologous T lymphoid in } \\
\text { vitro activated by i.p. route }\end{array}$ & Canevari S, et al. & JNCI Oct 1995;87:1463-9 & $\begin{array}{l}23 \text { treated patients Complete } \\
\text { response in } 3 \text { patients }(26,23,18 \\
\text { months) }\end{array}$ \\
\hline Colon cancer stage II & Surgery + Oncovax (BCG) & Uyl-de Groot CA, et al. & $\begin{array}{l}\text { Vaccine, } 2005 \text { Mar } \\
\text { 18;23(17-18):2379-87 }\end{array}$ & $\begin{array}{l}\text { Statistically improves } 5 \text { years } \\
\text { survival }\end{array}$ \\
\hline Melanoma & Advanced melanoma & $\begin{array}{l}\text { Stewart JH and EA } \\
\text { Levine }\end{array}$ & $\begin{array}{l}\text { Expert Rev of Antic Ther } \\
2011 ; 11: 1671-6\end{array}$ & $\begin{array}{l}\text { Statistically improves survival } \\
\text { compared to patients not treated } \\
\text { with BCG }\end{array}$ \\
\hline $\begin{array}{l}\text { Ovarian, Gastric cancer. } \\
\text { Regional immunotherapy } \\
\text { Systemic review of } 5 \text { years }\end{array}$ & $\begin{array}{l}\text { TILs, peripheral blood } \\
\text { mononuclear cells }\end{array}$ & Zeeltman $M$, et al. & Am J Surg Oct 2016 & $\begin{array}{l}\text { Increase of survival in the regional } \\
\text { administration of cell-based clinical } \\
\text { trials over the last } 5 \text { years }\end{array}$ \\
\hline
\end{tabular}


cae (SRL172) has been shown, in recent studies, to be effective in the treatment of adenocarcinoma of the lung and renal cell cancer. It is postulated that the mechanisms of this form of immunotherapy is, at least in part, due to immune regulation, reflected in the selective enhancement of Th1 and down-regulation of Th2 T cell activity $(47,48)$.

Immunotherapy of the ovarian tumor was reviewed recently. BCG interfering with CTLA-4 and PD-1 tumor's check point inhibitors have demonstrated clinical benefit in several human cancers. In order to generate effector $\mathrm{T}$ cells with ability to recognize tumor in vivo, cancer vaccines emerged as an immunotherapeutic approach, but a major question is identifying the most effective and safe vaccine targets in ovarian cancer and the effects of combined therapies $(49,50)$. Intralesional therapies can provide the necessary stimuli to trigger an innate immune response leading to the production of type I interferons and maturation and activation of dendritic cells that can cross-present tumor antigens to $\mathrm{T}$ cells. Intralesional therapies including BCG, viral therapies, inflammatory cytokines may act determining a tumor infiltration with $\mathrm{T}$ cells that are directed against tumor antigens leading to the production of type I interferons and maturation and activation of dendritic cells that can cross-present tumor antigens to T cells (51) Recently presented clinical and pre-clinical combination therapies have been developed to overcome resistance and have the potential to substantially extend the therapeutic reach of these revolutionary drugs $(52,53)$. On the other hand, over the years immunotherapy has become a promising and effective strategy for the treatment of various types of cancer, including ovarian cancer, but despite the clinical success of antibodies against the immune regulators CTLA4 and PD-L1/PD-1, only a subset of people exhibit durable responses suggesting that a broader view of cancer immunity is required (54).

Ovarian cancer is the leading cause of mortality from gynaecological malignancies, and novel treatment modalities, including immune therapy, especially anti-programmed cell death ligand-1/ programmed cell death-1 (PD-L1/PD-1) treatment is now focus of attention (55).

Since the presence of tumor infiltrating lymphocytes (TILs) is associated with improved clinical outcome in ovarian cancer patients (14), it was hypothesized that the quality of infiltrating $\mathrm{T}$ cells could also be a critical determinant of outcome in ovarian cancer patient. Nevertheless, it must be remembered that a significant inverse correlation was observed between PD-L1 expression and the intraepithelial $\mathrm{CD}^{+} \mathrm{T}$ lymphocyte count, suggesting that PD-L1 on tumor cells directly suppresses antitumor $\mathrm{CD}^{+} \mathrm{T}$ cells in ovarian cancer working in an analogous way as anti PD-L1 antibodies initiating the response of cytotoxic T-lymphocyte antigen 4 (CTLA-4) and programmed death receptor 1 (PD-1) $(55,56)$. In targeting DNA repair pathways of the most genomic instable cancer, poly-(adenosine diphosphate [ADP])-ribose polymerase inhibitors (PARPi) have been demonstrated as the most effective drug since platinum in high grade serous or endometrioid ovarian cancer. Immunotherapy is strongly pushing the door of ovarian cancer and has the ambition to change the fate of this deadly disease when combined with chemotherapy, vascular endothelial growth factor inhibitor or PARPi. The activity of PARPi could also be improved by modulators of the cell cycle, which are required to give time enough for DNA repair. Even more ambitious are drug targeting the driver p53 mutation or the pathway which inhibit tumor cell apoptosis (57). It was indeed recently found that programmed death-ligand (PD-L1) expression was upregulated in bladder rats cancer cells in response to BCG treatment both in vitro and in vivo. Moreover, BCG and anti-PD-L1 blockade therapy combination treatment activates a potent antitumor immune response with the increase in the number and activity of tumor-infiltrating $\mathrm{CD}^{+} \mathrm{T}$ cells, as well as the reduction in myeloid-derived suppressor cells (MDSCs). This kind of combination immunotherapy elicits prominent tumor growth inhibition and prolonged survival, and was found to be much more effective than either agent alone $(58,59)$.

The findings highlight the adaptive dynamic regulation of PD-L1 in response to BCG immunotherapy and suggest that BCG and anti PD-L1 combination therapy may be a promising antitumor strategy for improving treatment outcomes in BC as in other tumors.

As a conclusion, BCG immunotherapy might be tried in association with other anti CTLA-4 and PD-1, in tumor relapsing patients.

Concerning surgical immune interventions for solid malignancies, the search yielded 334 relevant publications. There has been an increase in the regional administration of cell-based and viral vector-based clinical trials over the last 5 years. Surgical interventions have been developed for intrapleural, intracranial, intraperitoneal, and intratumoral routes of access to enhance the local de- 
livery of these therapies. Multimodality therapies that combine regional immunotherapy with other local and systemic therapies are demonstrating continued growth as the field of immunotherapy continues to expand. Enormous progress has been made in the management of this disease, and new targeted treatments such as antiangiogenic drugs, poly (adenosine diphosphate-ribose) polymerase inhibitors, and immune checkpoint inhibitors offer potential for improved survival $(19,60)$.

As a summary, may be said that:

1. BCG used intradermally to improve an aspecifically immune reaction provokes only a feeble if any reaction against the tumor (8);

2. BCG as other viral agent (CAVATAK) may determine the complete recovery of the patient and the disappearance of tumor also in non-injected lesions $(9,10,20,31)$;

3. many patients have had other kind of therapies (surgery, chemotherapy) and are seen at different stages of their disease with different histologic characteristics: it is so sometimes difficult to understand if the improvement is caused by BCG or by other concomitant immunotherapy. This paper refers to the use of only BCG in patients in terminal stages of their ovarian cancers and no longer amenable to any other therapy (surgical or chemotherapy (4)).

Antigen-conjugated BCG-CWS vaccine is simple to manufacture, safe, and easy to use. Our results suggest that mycobacterial CWS as a universal vaccine vehicle for conjugation of a wide variety of antigens constitutes a breakthrough for development of the most promising vaccines for infections, allergic diseases, and cancer (61). However, despite all the advances made so far by immunotherapy and combination therapy, the next major challenge involves understanding and overcoming the innate and acquired resistance that prevents most patients from responding to PD-1/PD-L1 blockade. A recent overview of current FDA-approved drugs targeting PD-1 or PD-L1 summarized clinical progress so far (61).

\section{CONCLUSIONS}

The approach of intratumoral BCG in the ovarian tumors preceded other successive kind of immunotherapy attempts in other human malignancies as bladder cancer and melanoma and only recently we understood some of its mechanisms of action.
These attempts made in 1970, were the first kind of any human solid cancer immunotherapy, with the reports of 19 ovarian tumors patients, using intratumoral (direct) or intradermal BCG (indirect) injections. They have shown:

a. the first BCG intraparenchymal injection in the context of a primitive human solid tumor (ovarian) between 1971 and 1973;

b. the first demonstration that in a very advanced ovarian (TIII) tumor with peritoneal metastasis, complete disappearance of the primitive tumor and peritoneal metastasis were obtained as well as the recovery of the patient and her survival for 10 years, in the absence of any other associated therapy (surgical or chemotherapy);

c. in other two cases of parasternal subcutaneous metastasis BCG intralesional injection of the tumor was also done with a clear improvement in one terminal stage patient who gained $10 \mathrm{~kg}$ of weight and survived one year against any clinical expectation;

d. the first reports in which it was proposed that a close contact between BCG and tumoral cells may improve the anti-tumor activity immunological answer, perhaps modifying the tumoral antigen presentation to $\mathrm{T}$ lymphocytes;

e. the first observation that there is an absent or weak anti $\mathrm{M} t$ dermal reaction in gynecological advanced solid tumors and that this reaction can be changed with i.d. BCG repeated injections and becomes strong after 2-3 BCG vaccinations;

$\mathrm{f}$. the first demonstration that the aspecific i.d. BCG administration solicits also, in few patients, a delayed immune response to own tumoral antigen homogenate. This reaction improves the immune aggression of the tumor if the tumor is secondarily injected with BCG, as in the case of patient S.M. The response might be secondarily directed against the same tumor with intralesional injections of BCG or his derivative (BCSSW) thus can improving, in some patients, the T cells immune response against the tumor.

Successive immunotherapy cancer researches have substantially confirmed this initial immunological BCG anti-tumor approach, adopted later until now as golden standard therapy for bladder cancer and have clarified the association between lymphocytes tumor infiltration (as determined by intratumoral BCG) and life expectation.

BCG use in human ovarian tumors may perhaps have represented a right research premise for other successive studies of immunotherapy. 
Nevertheless the association of BCG with immunity anti-check point treatments might encourage further studies in patients resistant to anti PD1 and CTL-4 therapy given alone or showing autoimmune diseases in the course of such a therapy (60). BCG vaccine or its derivative may be still considered as useful tools in cancer immunotherapy.

Combination treatment of BCG with immune therapy anti CTLA-4 and anti PD-1 checkpoint blockade, which have distinct cellular mechanisms of action $(42,43)$, may give a more active and potent anti-tumor immune response and may be tried by further studies also in ovarian cancer $(42,43)$ where it is not understood and difficult to overcome the resistance of cancer to PD-1/PD-L1 blockade (57). Recent findings in the experimental animal model look promising, highlighting the adaptive dynamic regulation of PD-L1 in response to BCG immuno- therapy therapies and suggesting that a combination of BCG immunotherapy with PD-L1 blockade may be an effective antitumor strategy for improving treatment outcomes of $\mathrm{BCa}$ (58-61).

The use of i.d. or intratumor BCG especially SDWBCG can still be considered as part of the tools to cure or, joined to other immunotherapic strategies to treat human tumors. However, a lot of experience still needs to be done in this direction and since the first results obtained in humans in the early seventies (62), after almost 50 years much remains to be understood and improved.

\section{CONFLICT OF INTERESTS}

The author declares that he has no conflict of interests. 


\section{REFERENCES}

1. Okafor CN, Rewane A, Momodu II. Bacillus Calmette Guerin (BCG), Treasure Island (FL): Stat Pearls Publishing 2020.

2. Tarancón R, Domínguez-Andrés J, Uranga S, et al. New live attenuated tuberculosis vaccine MTBVAC induces trained immunity and confers protection against experimental lethal pneumonia. PLoS Pathog 2020;2;16(4):e1008404.

3. Choi IS, Koh YI. Therapeutic effects of BCG vaccination in adult asthmatic patients: a randomized, controlled trial. Ann Allergy Asthma Immunol 2002;88(6):584-91.

4. Centaro A, Carretti N. La diagnosi immunologica dei tumori ginecologici e la valutazione prognostica delle difese biologiche, Atti SIGO. $56^{\circ}$ Congresso Nazionale, Padova 1974;3-5:231-83.

5. Redelman-Sidi G, Glickman MS, Bochner BH. The mechanism of action of BCG therapy for bladder cancer--a current perspective. Nat Rev Urol 2014;11(3):153-62.

6. Fuge O, Vasdev N, Allchorne P, Green JS. Immunotherapy for bladder cancer. Res Rep Urol 2015;4(7):65-79.

7. Bellmunt J, Powles T, Vogelzang NJ. A review on the evolution of PD-1/PD-L1 immunotherapy for bladder cancer: The future is now. Cancer Treat Rev 2017;54:58-67.

8. Carretti N, Galli PA, Minucci D. L'ipersensibilità ritardata in vivo da Cacillus Calmette-Guerin (BCG) ed estratto tumorale in pazienti portatrici di neoplasia ginecologica. Atti del $56^{\circ}$ Congresso Nazionale della Società Italiana di Ostetricia e Ginecologia Padova, 3-5 Ottobre 1974:pp. 469-75.

9. Carretti N, Galli PA, De Salvia D, Minucci D. Considerazioni su due casi di neoplasie ginecologiche inoperabili trattati con inoculazione di BCG nella massa neoplastica. Atti del $56^{\circ}$ Congresso Nazionale della Società Italiana di Ostetricia e Ginecologia Padova, 3-5 Ottobre 1974:pp. 465-468.

10. Carretti N. Trattamento con BCG di metastasi sottocutanee di tumore ovarico e regressione temporanea del tumore. Atti del $56^{\circ}$ Congresso Nazionale della Società Italiana di Ostetricia e Ginecologia. Padova, 3-5 Ottobre 1974:pp. 476-9.

11. Kigoshi S, Nishio M, Oshita M. Cytotoxicity of cortisone-resistant lymphocytes from mice treated with a group A streptococcus or Freund's complete adjuvant against tumor cells. Cytotoxicity of cortisone-resistant lymphocytes from mice treated with a group A streptococcus or Fre- und's complete adjuvant against tumor cells. Jpn J Pharmacol 1985;39(2):225-32.

12. Azuma I, Seya T. Development of immunoadjuvants for immunotherapy of cancer. Int Immunopharmacol 2001;1(7):1249-59.

13. Kaham BD. Solubilization of allospecific and tumor-specific cell surfaceantigens, "Methods in Cancer Research" IX,283, 1973. Ed.H. Bush. Academic Press 2001;1(7):1249-59.

14. Hwang WT, Adams SF, Tahirovic E, HagemannIS, Coukos G. Prognostic significance of tumor-infiltrating $\mathrm{T}$ cells in ovarian cancer: a meta-analysis. Gynaecol Oncol 2012;124(2):192-8.

15. Hendry S, Salgado R, Gevaert T, et al. Assessing Tumor-Infiltrating Lymphocytes in Solid Tumors: A Practical Review for Pathologists and Proposal for a Standardized Method from the International Immuno-Oncology Biomarkers Working Group: Part 2: TILs in Melanoma, Gastrointestinal Tract Carcinomas, Non-Small Cell Lung Carcinoma and Mesothelioma, Endometrial and Ovarian Carcinomas, Squamous Cell Carcinoma of the Head and Neck, Genitourinary Carcinomas, and Primary Brain Tumors. Adv Anat Pathol 2017;24(6):311-35.

16. Hayashi A, Nishida Y, Yoshii S, Kim SY, Uda H, Hamasaki T. Immunotherapy of ovarian cancer with cell wall skeleton of Mycobacterium bovis Bacillus Calmette-Guérin: effect of lymphadenectomy. Cancer Sci 2009;100(10):1991-5.

17. Deng YH, Sun Z, Yang XL, Bao L. Improved immunogenicity of recombinant Mycobacterium bovis bacillus Calmette-Guérin strains expressing fusion protein Ag85A- ESAT-6 of Mycobacterium tuberculosis. Scand J Immunol 2010;72(4):332-8.

18. Azuma I, Seya T. Development of immunoadjuvants for immunotherapy of cancer. Int Immunopharmacol 2001;1(7):1249-59

19. Paik TH, Lee JS, Kim KH, Yang CS, Jo EK, Song $\mathrm{CH}$. Mycobacterial cell-wall skeleton as a universal vaccine vehicle for antigen conjugation. Vaccine 2010;28(50):7873-80.

20. Waisbren BA. Update on the treatment of cancer with multiple immunotherapy. Cancer Biother Radiopharm 1999;14(1):27-30.

21. Corrado G, Palluzzi E, Bottoni C, et al. New medical approaches in advanced ovarian cancer. Minerva Medica 2019;110(4):367-84.

22. Bast RC Jr, Berek JS, Obrist R, et al. Intraperitoneal immunotherapy of human ovarian carcinoma with Corynebacterium parvum. Cancer Res 1983;43:1395-1401. 
23. Hennequin A, Derangere V, Boidot R, et al. Tumor infiltration by Tbet+ effector T cells and CD20+ $\mathrm{B}$ cells is associated with survival in gastric cancer patients. Oncoimmunol 2016;5:e1054598

24. Xu Y, Chena L, Xu B, et al. Higher Numbers of T-BetTumor- Infiltrating Lymphocytes Associate with Better Survival in Human Epithelial Ovarian Cancer. Cell Physiol Biochem 2017;41:475-483

25. Zhang L, Conejo-Garcia JR, Katsaros D, et al. Intratumoral $\mathrm{T}$ cells, recurrence, and survival in epithelial ovarian cancer. Eng J Med 2003;348(3):203-13.

26. Popiela T, Kulig J, Czupryna A, Szczepanik AM, Zembala M. Efficiency of adjuvant immunochemotherapy following curative resection in patients with locally advanced gastric cancer. Gastric Cancer 2004;7(4):240-5.

27. Goerè D, Gras-Chaput N, Aupérin A, et al. Treatment of gastric peritoneal carcinomatosis by combining complete surgical resection of lesions and intraperitoneal immunotherapy using catumaxomab. BMC Cancer 2014 ;4:14-148.

28. YaoK, Wang W, Li H, et al. Bacillus CalmetteGuérin (BCG) activates lymphocyte to promote autophagy and apoptosis of gastric cancer MGC-803 cell. Cell Mol Biol (Noisy-le-grand) 2018;64(6):11-6.

29. Redelman-Sidi G, Binyamin A, Gaeta I, et al. The Canonical Wnt Pathway Drives Macropinocytosis in Cancer. Cancer Res 2018;78(16):4658-70.

30. Uyl-de Groot CA, Vermorken JB, Hanna Jr MG, et al. Immunotherapy With Autologous Tumor cellBCG Vaccine in Patients With Colon Cancer: A Prospective Study of Medical and Economic Benefits. Vaccine 2005;23(17-18):2379-87.

31. Nishida S, Tsuboi A, Tanemura A, et al. Immune adjuvant therapy using Bacillus Calmette-Guérin cell wall skeleton (BCG-CWS) in advanced malignancies: A phase 1 study of safety and immunogenicity assessments. Med 2019;98(33):e16771.

32. Morales A. BCG: A throwback from the stone age of vaccines opened the path for bladder cancer immunotherapy Review. Can J Urol 2017;24(3):8788-93.

33. Morales A, Eidinger D, Bruce AW. Intracavitary bacillus Calmette-Guerin in the treatment of superficial bladder tumors. J Urol 1976;116:180-3.

34. Herr HW, Morales A. History of bacillus Calmette-Guerin and bladder cancer: an immunotherapy success story. J Urol 2008;179(1):53-6.

35. Fuge O, Vasdev N, Allchorne P, Green JS. Immunotherapy for bladder cancer. Res Rep Urol 2015;7:65-79.
36. Kamat M, Porten S. Miths and Mysteries surrounding bacillus Calmette-Guirin therapy for bladder cancer. European Urology 2014;65:267-9.

37. Ślusarczyk A, Zapała P, Zapała Ł, Piecha T, Radziszewski P. Prediction of BCG responses in non-muscle-invasive bladder cancer in the era of novel immunotherapeutics. Int Urol Nephrol 2019;51(7):1089-99.

38. Benitez MLR, Bender CB, Oliveira TL, Schachtschneider KM, Collares T, Seixas FK. Mycobacterium bovis BCG in metastatic melanoma therapy. Appl Microbiol Biotechnol 2019;103(19):7903-16.

39. Abbott AM, Zager JS. Locoregional therapies in melanoma. Surg Clin North Am 2014;94(5):1003;124(2):192.

40. Ruiz Benitez ML, Bonnemann Bender C, et al. Mycobacterium bovis BCG in metastatic melanoma therapy. Appl Microbiol Biotechnol 2019;103(19):7903-16.

41. Stewart JH, Levine EA. Role of bacillus CalmetteGuérin in the treatment of advanced melanoma. Expert Rev Anticancer Ther 2011;11(11):1671-6.

42. Hamid O, Ismail $\mathrm{R}$, Puzanov I. Intratumoral Immunotherapy-Update 2019. Oncol 2020;25(3):e423-e438.

43. Kuo CH, Lo CY, Chung FT, et al. Concomitant Active Tuberculosis Prolongs Survival in NonSmall Cell Lung Cancer: A Study in a Tuberculosis- Endemic CountryPlos One 2012;7(3).

44. Ribas A, Wolchok JD. Cancer immunotherapy using checkpoint blockade. Science 2018;359(6382):1350-5.

45. Sharma P, Allison JP. The future of immune checkpoint therapy. Science 2015;348(6230):56-61.

46. Udagawa M, Kudo-Saito C, Hasegawa G, et al. Enhancement of immunologic tumor regression by intratumoral administration of dendritic cells in combination with cryoablative tumor pretreatment and Bacillus Calmette-Guerin cell wall skeleton stimulation. Clin Cancer Res 2006;12(24):7465-75.

47. Wei SC, Levine JH, Cogdill AP, et al. Distinct Cellular Mechanisms Underlie Anti-CTLA-4 and Anti-PD-1 Checkpoint Blockade. Cell 2017;170(6):1120-33.e17.

48. Chen DS, Mellman I. Elements of cancer immunity and the cancer-immune set point. Nature 2017;541(7637):321-30.

49. Foon KA, Fanning J. Immunotherapy of gynecologic malignancies. Semin Surg Oncol 1990;6(6):364-8.

50. Pujade-Lauraine E. New treatments in ovarian cancer. Ann Oncol 2017;28(8):57-60. 
51. Pignata S, Cecere S, Du Bois A, Harter P, Heitz F. Treatment of recurrent ovarian cancer. Ann Oncol 2017;28(8):51-6.

52. Ledermann JA. Front-line therapy of advanced ovarian cancer: new approaches. Ann Oncol 2017;28(8):46-50.

53. Hargadon KM, Johnson CE, Williams CJ. Understanding and overcoming the resistance of cancer to PD-1/PD-L1 blockade. Pharmacol Res 2019;145:10425.

54. Mandai M, Hamanishi J, Abiko K, Matsumura N, Baba T, Konishi I. Anti-PD-L1/PD-1 immune therapies in ovarian cancer: basic mechanism and future clinical application. Int J Clin Oncol 2016;21(3):456-61.

55. Odunsi K. Immunotherapy of ovarian cancer. Ann Oncol 2017;28(8):1-7.

56. Hamanishi J, Mandai M, Iwasaki M, et al. Programmed cell death 1 ligand 1 and tumor-infiltrating CD8+ T lymphocytes are prognostic factors of human ovarian cancer. Proc Natl Acad Sci USA 2007;104(9):3360-5.
57. Kyi C, Postow MA. Immune checkpoint inhibitor combinations in solid tumors: opportunities and challenges. Immunother 2016;8(7)821-37.

58. Wang Y, Liu J, Yang X, et al. Bacillus CalmetteGuérin and anti-PD-L1 combination therapy boosts immune response against bladder cancer. Oncol Targets Ther 2018;11:2891-9.

59. Pujade-Lauraine E. New treatments in ovarian cancer. Ann Oncol 2017;28(8):57-60.

60. Zeltsman M, Mayor M, Jones DR, Adusumilli PS. Surgical immune interventions for solid malignancies. Am J Surg 2016;212(4):682-90.

61. Shergold AL, Millar R, Nibbs RJB. Understanding and overcoming the resistance of cancer to PD-1/PD-L1 blockade. Pharmacol Res 2019;145:104258.

62. Mathé G, Hayat M, Amiel JL, et al. Active immunotherapy in the treatment of experimental leukemias and acute lymphoblastic leukemia in man, Boll Ist. Sieroter Milan 1971;50(4):251-9. 